\title{
THE IMPACT OF STRENGTHENING COMMUNITY HEALTH SERVICES ON COMMUNITY UTILIZATION OF MALARIA CONTROL INTERVENTIONS IN MIGORI AND KWALE COUNTIES (A BASELINE SURVEY STUDY)
}

\author{
Athuman Nyae Chiguzo ${ }^{1 *}$, Helen Lydiah Kutima², Evan Murimi Mathenge ${ }^{3}$, \\ Charles Mwaniki Mbogo ${ }^{4}$
}

\begin{abstract}
${ }^{1}$ Institute of Tropical Medicine and Infectious Diseases Jomo Kenyatta University of Agriculture and Technology. P.0 Box 62000-00200, Nairobi, Kenya. ${ }^{2}$ Jomo Kenyatta University of Agriculture and Technology (JKUAT), P.O Box 62000-00200, Nairobi, Kenya. ${ }^{3}$ Kenya Medical Research Institute (KEMRI), P.0 Box 54840-00200, Nairobi, Kenya. ${ }^{4}$ KEMRI/Wellcome Trust Research Programme, P.0. Box 43640-00100 Nairobi, Kenya. *Corresponding Author’s Email:athuman.chiguzo@gmail.com
\end{abstract}

\begin{abstract}
Community health services are the mechanism through which households and communities increase their knowledge and skills in disease control and plan interventions. A mixed method cross-sectional baseline household survey was carried out in Migori and Kwale counties which constituted the intervention and control study sites respectively. The primary study participants were heads of households while secondary were FGDs and KIIs. Mean annual malaria cases for those above five years for all facilities in Migori County were 154/1000 compared to 113/1000 in Kwale. Mean annual malaria morbidity among children under five in all health facilities in Migori was 132/1000 compared to 32/1000 in Kwale. Net ownership among households in Migori was $65.8 \%$ compared to 31.4\% Kwale. Pregnant women attending ANC in Migori was $60.0 \%$ compared to $92.9 \%$ in Kwale. $20 \%$ of pregnant women received IPTp3 in Migori was compared to $18.2 \%$ in Kwale. Malaria incidence in Migori was 36.73\% compared to $63.7 \%$ for Kwale. Nets in use the night before survey by pregnant women in Migori was $38.6 \%$ compared to Kwale that was $28.5 \%$. Proportion tested for malaria in Migori was $45.3 \%$ compared to Kwale that was $40 \%$.

$32.9 \%$ of household respondents in Migori took ACT within 24 hours after fever started was compared to $8 \%$ in Kwale. The study concludes that community health units exist within the two counties and thus provides opportunities to strengthening community health services to achieve access and utilization of malaria control interventions at this level.
\end{abstract}

Key words: Malaria, Community Health Services, Community Health Volunteers, Households.

\section{INTRODUCTION}

Malaria is a preventable and treatable mosquitoborne disease, whose main victims are children under five years of age in Africa. The World Malaria Report 2012 summarized data received from 104 malaria-endemic countries and territories for 2011. Ninety-nine of these countries had on-going malaria transmission. According to the World Health Organization (WHO) estimates, there were about 219 million cases of malaria in 2010 and an estimated 660000 deaths (1).

(C)The Author(s) 2021. Published by Iquz Galaxy Publisher, India.. This is an Open Access article distributed under the terms of the Creative Commons Attribution CC BY license (http://creativecommons.org/licenses/by/4.0/), which permits unrestricted reuse, distribution, and reproduction in any medium, provided the original work is properly cited.

(Received 22 April 2021; Revised 27 May 2021; Accepted 17 June 2021) 
Africa is the most affected continent: about $90 \%$ of all malaria deaths occur in the continent. The period between year 2000 and 2010, an estimated 1.1 million malaria deaths were averted globally, primarily as a result of a scale-up of interventions $(2,3)$.

The Global Malaria strategy follows a four-pronged approach and includes, access to prompt diagnosis and appropriate treatment; prevention of malaria in pregnancy; vector control through the use of Long Lasting Insecticidal Nets (LLINs), Indoor Residual Spraying (IRS) and other control methods as well as a swift response to emergencies and epidemics.

Malaria is the leading cause of morbidity and mortality in Kenya, accounting for $34 \%$ of the outpatient attendance in 2011 (4). Despite considerable efforts to control and treat the disease, the Kenya Demographic and Health Survey (5) estimated that about 24 million Kenyans were at risk of infection each year, with the most affected being pregnant women and children. Malaria affects pregnant women which lead to negative health for mother and baby, including anaemia, low birth weight and infant deaths, and it is one of the most common causes of spontaneous abortion. In addition, the ill health associated with the disease exerts devastating toll on social and economic productivity, undermining local development in some communities (5).

Malaria is the leading cause of morbidity and mortality and accounted for $40 \%$ (6) and $30 \%$ of the outpatient attendance in 2011 in Migori and Kwale counties respectively. Perhaps, one reason for this high morbidity is the lack of capacity to deliver malaria interventions to all who need them. According to the Ministry of Health (MOH) Community Health Strategy 2006 (7), communitybased approach, as set out in this strategy, is the mechanism through which households and communities strengthen their role in health and health-related development issues, by increasing their knowledge and skills in disease control and planning for health interventions. The overall goal of the community health strategy is to enhance community access to health care in order to improve productivity and thus reduce poverty, hunger, child and maternal deaths, as well as improve educational performance (7). This strategy is driven by Community Health Volunteers (CHVs). These are individuals chosen by the community and trained to address health issues of individuals, households and communities in their localities, working in collaboration with community leaders and link healthcare facilities staff. The CHVs are catalysts, whose role is to enable individuals take control of their health, and serve as a link to the healthcare facilities when the individuals need it (7).

\section{MATERIALS AND METHODS}

\subsection{Study Area and Study Design}

Two counties with similar malaria endemicity, socioeconomic characteristics, geographical features, climate/weather condition and, demographic characteristics were compared before and after intervention. One county served as a control (nonintervention).The two counties are Migori County in the former Nyanza Province, (Intervention) and Kwale County in the former Coast Province (Control). In Migori County, the study was carried out in four (4) community health units of Nyamagagana and Gosebe in Kuria West Sub County and Itongo and Getongoroma in Kuria East Sub County. In Kwale County the study was carried out in four (4) community health units' of Eshu and Mafisini in Msambweni Sub County and Mamba and Kikoneni in Lungalunga sub county.

A cross-sectional study designed to establish baseline information to guide the implementation of a community-based comparative analytical intervention study design to measure the differences in survey findings at baseline and four (4) years post intervention follow up surveys was carried out. In each of the counties, four (4) Community Health Units (CHUs) each with an approximately population of 5,000 people were selected. In the Intervention County (Migori), four (4) identified CHUs were selected and established. Fourty Community Health Volunteers (CHVs) from the established CHUs were trained on community strategy as well as malaria prevention and control interventions using $\mathrm{MOH}$ malaria Control unit approved training guidelines. A 
baseline survey in each of the counties was conducted to act as the pre-data for the intervention and control counties. The cross-sectional study was carried out in the two counties, collecting both quantitative and qualitative data.

\subsection{Sample Methodology and Study Population}

The study population included household members and key informants who lived within the stratified study area in both Migori and Kwale Counties. Sample size was determined using simple random sampling of households in the stratified study area in both Migori and Kwale Counties to establish baseline information on access and utilization of malaria control interventions with a $5 \%$ level of precision. The quantitative sample size was determined as described by Yamane, Taro (1967) (8) to establish baseline information on community usage of malaria control intervention in Migori and Kwale Counties, the $\mathrm{p}$ value was assumed to be 0.5 to give a sample size of 392. At baseline, the study conducted 1206 and 878 household interviews in Migori and Kwale counties respectively. Eight (8) Focus Group Discussions (FGDs) were conducted at each of the study sites (Intervention and Control).

The FGDs were conducted for groups of women and men in each of the CHU giving the total of 8 as stated above. Key Informants Interviews (KIIs) were conducted with Sub county MOHs, Sub county malaria coordinators, opinion leaders and community health strategy coordinators making a total of 8 KIIs per study site.

\subsection{Data Collection Tools}

Focus group and in-depth interview guides were used to generate qualitative data. Questionnaires, Rapid Diagnostic Tests (RDT) and Artemisinin-Based Combination Therapy (ACTs) consumption data tools were used to generate quantitative data. All research tools were pre tested in a local area and revised subsequently.

\subsection{Data Management and Analysis}

Various quality control measures were placed to ensure the quality of information collected was guarded. The measures included involvement of suitable fieldworkers and training them on the study protocol, pre-testing of study tools and supervision during data collection. To ensure quality, triangulation and validation was done using mixed methods for quantitative and qualitative as well as through different data sources. Quantitative data captured in questionnaires were coded after collection and double entered in MS Access. Any inconsistencies were dealt with immediately. To ensure consistency and completeness in qualitative data, clear requirements for the tools were continually expressed to the data collectors. At the end of each FGD and in-depth interview, there was debriefing about the salient issues arising out of the process, anomalies that occurred and what their overall opinions of the discussion/interview were. Quantitative data was entered in EPI-INFO version 7.2.1.0 and analyzed using STAT version 11.2, and finally presented in tables and text. Qualitative data were sorted, aggregated from the 8 FGDs and responses of each FGD Participants, then were entered by the researcher into tables broken down into themes and finally presented in tables and text. Distinctive quotes transcribed from the hand written interviews were noted in all tables and finally presented in text.

\section{RESULTS AND DISCUSSIONS 3.1 RESULTS \\ 3.1.1 Characteristics of the Study Population}

There were a total of 1206 and 878 households involved in the baseline survey in Migori and Kwale respectively. From these households a total of 6374 and 5529 people had their information recorded for the purpose of the research during the baseline in Migori and Kwale respectively. The average family size was 5.9 in both Migori and Kwale Counties. Gender balance was equal in the research, $49.6 \%$ were males and $50.4 \%$ were females in both counties (Table I) 
Table I: Socio-Economic and Demographic Characteristics of Household Respondents by County

\begin{tabular}{|l|c|c|}
\hline Characteristics & Migori & Kwale \\
\hline Household visited & 1206 & 578 \\
\hline Population covered & 6374 & $436(49.63 \%)$ \\
\hline Gender & $598(49.6 \%)$ & $442(50.37 \%)$ \\
\hline Male & $608(50.4 \% 0$ & 5.9 \\
\hline Female & 5.9 & 2.0 \\
\hline Average size of household & 1.0 & 10.0 \\
\hline Minimum & 11.0 & 5.0 \\
\hline Maximum & 4.5 & 2.0 \\
\hline Average size of land (acres) & 0.0 & 24.0 \\
\hline Minimum & 35.0 & $878(100 \%)$ \\
\hline Maximum & & $0(0 \%)$ \\
\hline Source of income & $1034(85.7 \%)$ & $0(0 \%)$ \\
\hline Farming & $71(5.9 \%)$ & $0(0 \%)$ \\
\hline Self- Employment & $25(2.1 \%)$ & $0(0 \%)$ \\
\hline Formal Employment & $52(4.3 \%)$ & $24(2.0 \%)$ \\
\hline Business & & \\
\hline None & \multicolumn{2}{|c|}{} \\
\hline
\end{tabular}

\subsubsection{Access and Use of Malaria Control Intervention}

Net ownership among households was lower in Migori compared to Kwale County (Table II). However, net use among the various target groups is comparable in both counties other than children under five in Kwale had a higher use than Migori (Table II).

The study established that households with at least one malaria case incidence in Migori are lower compared to Kwale County (Table II).

The proportion of Pregnant Women currently attending ANC in Migori was found to be higher compared to that of Kwale (Table II).

\subsubsection{Access and Use of Malaria Control Intervention FGDS Findings}

During FGD, access to diagnosis and treatment use was found to be similar in both Migori and Kwale counties with the former experiencing higher malaria cases at the household compared to the later (Table III).

All respondents (100\%) received ACTs from public health facilities while they received none from CHVs in both Migori and Kwale. (Table III).

Majority $(80 \%)$ of the respondents did not know how many times a pregnant woman must take malaria prophylaxis medicine (IPTp).

"I am not aware that pregnant women get malaria medicine for prevention. I even do not know how 
many times they are supposed to take". A woman respondent from Glory women group in Kuria East Sub County during the baseline survey.

Most of the respondents (64\%) mentioned community health volunteers (CHVs) as the best placed to provide malaria medicine at the community level in both Migori and Kwale Counties.
"CHVs are with us in the community. They visit us regularly. So, if they have malaria medicine in their drug kits, they can be of great assistance to us". A man respondent from Masaba men group in Kuria West Sub County during the baseline survey.

Table II. Comparisons of Selected Indicators in the Intervention Site Versus The Non-Intervention Site

\begin{tabular}{|c|c|c|}
\hline INDICATOR & $\begin{array}{l}\text { MIGORI } \\
\text { Baseline \% }\end{array}$ & $\begin{array}{l}\text { KWALE } \\
\text { Baseline \% }\end{array}$ \\
\hline \multicolumn{3}{|l|}{ Net ownership and utilization } \\
\hline Households with at least one mosquito net & 65.8 & 92.9 \\
\hline $\begin{array}{l}\text { Nets in use the night before survey by households' } \\
\text { members }\end{array}$ & 39.3 & 21.9 \\
\hline $\begin{array}{l}\text { Nets in use the night before survey by children } \\
\text { under five years }\end{array}$ & 36.7 & 68.0 \\
\hline $\begin{array}{l}\text { Nets in use the night before survey by pregnant } \\
\text { women }\end{array}$ & 38.6 & 28.5 \\
\hline \multicolumn{3}{|c|}{ Access to diagnosis treatment and utilization of case management of malaria } \\
\hline $\begin{array}{l}\text { Households with at least one malaria case } \\
\text { incidence }\end{array}$ & 36.73 & 63.7 \\
\hline Proportion tested for malaria & 45.3 & 40.0 \\
\hline $\begin{array}{l}\text { How long after fever started was ACT taken } \\
\text { within } 24 \text { hours }\end{array}$ & 32.9 & 8.0 \\
\hline \multicolumn{3}{|c|}{ Access and utilization of malaria prevention in pregnancy } \\
\hline Pregnant Women currently attending ANC & 60.0 & 31.4 \\
\hline ANC attending women who have received IPTp 2 & 29.1 & 31.4 \\
\hline ANC attending women who have received IPTp 3 & 20.0 & 18.2 \\
\hline
\end{tabular}


Table III. Access to Diagnosis and Treatment Use FGD Findings Migori and Kwale

\begin{tabular}{|l|c|c|}
\hline & Migori & Kwale \\
\hline Indicator & Baseline findings & Baseline findings \\
\hline $\begin{array}{l}\text { Households with at least one } \\
\text { malaria case incidence }\end{array}$ & $97.36 \%$ & $70.3 \%$ \\
\hline Proportion tested for malaria & $61.9 \%$ & $09 \%$ \\
\hline Test performed by CHV & $0 \%$ & $100 \%$ \\
\hline Malaria test results positive & $100 \%$ & $0 \%$ \\
\hline Malaria test results negative & $0 \%$ & $30 \%$ \\
\hline $\begin{array}{l}\text { How long after fever started was } \\
\text { ACT taken within 24 hours }\end{array}$ & $53.8 \%$ & $0 \%$ \\
\hline Positive cases that received ACT & $100 \%$ & $100 \%$ \\
\hline $\begin{array}{l}\text { Negative cases that received } \\
\text { ACT }\end{array}$ & $0 \%$ & $0 \%$ \\
\hline $\begin{array}{l}\text { Those who received ACT from } \\
\text { public health facilities }\end{array}$ & $0 \%$ & \\
\hline $\begin{array}{l}\text { Those who received ACT from } \\
\text { CHV }\end{array}$ & & \\
\hline
\end{tabular}

\subsection{DISCUSSION}

The baseline report established that the socialeconomic and demographic profiles were similar in both Migori and Kwale counties. These findings are consistent with the Kenya population and housing census 2019 as well as Kwale County integrated development plan 2018-2022 (9-11). Thus, the two counties were found as ideal sites for a comparative study by one being an intervention and the other a control.

The study found out that Migori was experiencing higher malaria cases at the household compared to Kwale. This is consistent with the findings of the malaria indicator surveys 2011, where the lake endemic zone (Migori included) had the highest prevalence of malaria overall (38\%) compared to Kwale $(<20 \%)(12,13)$.
Majority of the respondents mentioned they receive ACTs from public health facilities while none from CHVs. There is therefore a gap in access to ACTs as most community members were not within close reach to a health facility. In the FGDs, community recognized the presence of CHVs in their midst and suggested them to be suitable for providing access to malaria medicine as well as constant reminders to household about malaria control and prevention intervention and other health issues. There were a number of basic routine services available at the community level. In most community health services, CHVs offers health education, referral to link facilities, mobilization of children for immunization, family planning methods distribution, treatment of common ailments, as well as distribution of oral rehydration supplies (14). These findings are similar as those described by Rose Njiraini and Salim Hussein in Kenya as well as George Mwinnyaa et al., in Ghana (15), (16). A study by Wofak demonstrated that the level of 
satisfaction with work as CHVs was generally high and thus presented a great opportunity for integrating Malaria, HIV and TB at the community level. However, there existed gaps such as inadequate training, motivation of CHVs including stipend, stock-out of tools, and lack of necessary equipment and supplies that needed to be addressed prior to implementation of the integrated services model (14).The baseline survey found that the awareness of the community about malaria prevention using IPTp was very low, perhaps this is because of the low utilization of IPTp3 which is also consistent with the findings of the malaria indicator surveys 2011 and $2015(12,13)$.

\section{CONCLUSION}

It can be concluded from this study findings that the two counties have similar socio-economic and demographic profiles and thus can form ideal sites for a comparative study by one being an intervention and the other a control.

A clear opportunity identified within each of the counties was the presence of existing community health units and opportunity to form new ones as well as CHVs who provide community health services. Other opportunities included the goodwill from the county governments, partners support, availability of commodities and equipment, joint planning and existing county and sub-county health management teams who review the progress of implementation and offer guidance and supervision.

The study concludes that with low established knowledge and utilization of malaria control intervention in both counties, there is an opportunity for strengthening through establishing community health units as well as training of community health volunteers to take the mantle of social and behaviour change and communication at the household and community level.

\section{ACKNOWLEDGEMENTS}

We wish to convey our gratitude to the research teams both in Kwale and Migori Counties that participated in data collection. Thanks to the
Director KeNAAM who was able to link me with his Global Fund Malaria project team in Migori. Special thanks to all the participants who took part in the study. Special thanks go to my supervisors who have been of great encouragement to me and have constructively critiqued this study to make it better. I would also like to appreciate the timely support and encouragement from the management of Jomo Kenyatta University of Agriculture and Technology (JKUAT), and KEMRI. We would like to acknowledge the Director KEMRI.

\section{CONFLICT OF INTEREST}

There is no conflict of interest in this present research paper. This research work is not a part of any other studies and it is our original work.

\section{REFERENCES}

1. World Health Organization (WHO). World malaria report 2011. Geneva, 2011, (http://www.who.int/entity/malaria/world_malaria_ report 2011/9789241564403_eng.pdf, accessed 10 November 2012).

2. WHO, 2012. Global plan for insecticide resistance management in malaria vectors (GPIRM). Geneva: World Health Organization, 2012.

3. Kenya National Bureau of Statistics and ICF M ACRO. Kenya Malaria Indicator Survey (KNMS), DOMC, National Malaria Strategy 2009-2017, 2009.

4. Kenya National Bureau of Statistics and ICF MACRO. Kenya Demographic Health Survey 2008-2009, 2010.

5. Kenya National Bureau of Statistics, Population Services International Kenya, ICF Macro and Division of Malaria Control [Ministry of Public Health and Sanitation], Evaluation of the Post Mass Net Distribution Programme 2011/12, 2012.

6. Migori County Government. Migori County malaria profile, 2012.

7. Ministry of health, Kenya. Taking the Kenya Essential Package for Health to the community. A strategy for Delivering of Level One Services, Nairobi Kenya, 2006.

8. Yamane, Taro. Statistics. An introductory analysis, 2nd Edition, New York, Harper and Row. 1967.

9. Kenya National Bureau of Statistics (KNBS): Kenya Population and Housing Census volume II, December, 2019.

10. Kwale County Government. Kwale County integrated development plan 2018-2022, 2019.

11. Odero Collince Omondi. Behavioural, Environmental, Socioeconomic and Demographic determinants of diarrhoea morbidity among children under 5 years in Migori County, Kenya. MPH thesis, 2017. The School of Public Health of Kenyatta University, Kenya

12. Division of Malaria Control [Ministry of Public Health 
and Sanitation], Kenya National Bureau of Statistics, and ICF Macro. 2010 Kenya Malaria Indicator Survey. Nairobi, Kenya: DOMC, KNBS and ICF Macro, 2011.

13. Kenya National Bureau of Statistics and ICF Macro, Editor. Kenya Malaria Indicator Survey 2015 (NMCP), 2016: Nairobi Kenya.

14. Community System Strengthening TWG. Baseline Survey on The Integrated HIV, TB and Malaria Services at the Community Level in Rangwe, Emuhaya and Lungalunga Sub-Counties, Kenya , 2017.
15. Rose Njiraini and Salim Hussein. Kenya's Community Health Volunteer Program, 2019. CHW Central. A global Resource for and about community health workers.

16. George Mwinnyaa, Tanya C. Jones, Patricia Antwi, Elizabeth Chan, James F. Phillips, and John Koku Awoonor-Williams. Ghana's Community Health Officers and Community Health Volunteers, 2020. CHW Central. A global Resource for and about community health workers. 